\title{
Maternal Cardiovascular Hemodynamics in Preeclampsia: Echocardiographic Assessment and Evaluation of Subclinical Left Ventricular Dysfunction
}

\author{
${ }^{1}$ Nuzhat Zaman, ${ }^{2}$ Nasar Abdali, ${ }^{3}$ Mohammed Asif, ${ }^{4}$ Pradyot Tiwari, ${ }^{5}$ Mohd Mahmudullah Razi
}

\begin{abstract}
Background: Preeclampsia is a disorder of pregnancy having an impact on multiple organ systems. Cardiac manifestations in preeclampsia are varied which can be easily studied by echocardiography. With the advancement in the field of strain imaging, we can also analyze and predict the subclinical left ventricular dysfunction in these patients which may help us to assess high-risk groups.
\end{abstract}

Objective: To compare maternal cardiovascular hemodynamics and function with emphasis on diastolic parameters and strain imaging using echocardiography in normal pregnant women with those having preeclampsia in the third trimester of pregnancy.

Methods: Thirty preeclamptic women and 30 women with a normal singleton pregnancy of 34 weeks gestation were compared for systolic and diastolic parameters on echocardiography. Strain imaging was done to find the global and circumferential strain.

Results: Blood pressure and total vascular resistance were significantly more in preeclamptic subjects than control. Women with preeclampsia had more diastolic dysfunction than those having a normal pregnancy. The global longitudinal strain was less in the preeclamptic group $(-15.63 \pm 1.69)$ than control $(-20.86 \pm 1.52)$. Similarly, the circumferential strain was lower in the preeclamptic group $(-16.93 \pm 1.11)$ than control $(-21.76 \pm 1.25)$.

Conclusion: Preeclamptic women have a significant difference in systolic and diastolic dysfunction as compared to pregnant females having normal blood pressure. Early assessment of these parameters may help to identify the high-risk groups. Knowledge of these changes may help us to understand better the pathophysiological basis of disease which may further help in managing these patients.

Keywords: Echocardiography, Left ventricular dysfunction, Preeclampsia.

How to cite this article: Zaman N, Abdali N, Asif M, Tiwari P, Razi MM. Maternal Cardiovascular Hemodynamics in Preeclampsia: Echocardiographic Assessment and Evaluation of Subclinical Left Ventricular Dysfunction. J South Asian Feder Obst Gynae 2018;10(Suppl 2):400-404.

\footnotetext{
${ }^{1}$ Resident, ${ }^{2-4}$ Senior Resident, ${ }^{5}$ Lecturer

${ }^{1}$ Department of Obstetrics and Gynecology, Maulana Azad Medical College, New Delhi, India

${ }^{2-5}$ Department of Cardiology, LPS Institute of Cardiology, Ganesh Shankar Vidyarthi Memorial Medical College, Kanpur, Uttar Pradesh, India

Corresponding Author: Nasar Abdali, Senior Resident, Department of Cardiology, LPS Institute of Cardiology, Ganesh Shankar Vidyarthi Memorial Medical College, Kanpur, Uttar Pradesh, India, e-mail: editor.hadi@gmail.com
}

\section{Source of support: Nil}

Conflict of interest: None

Date of received: 25 November 2016

Date of acceptance: 9 June 2017

Date of publication: July 2019

\section{BACKGROUND}

Preeclampsia is a disorder of pregnancy characterized by new-onset hypertension, i.e., systolic blood pressure $\geq 140 \mathrm{~mm} \mathrm{Hg}$ or diastolic blood pressure $\geq 90 \mathrm{~mm} \mathrm{Hg}$ developing after 20 weeks of gestation with the involvement of at least one organ system which completely resolves within 12 weeks postpartum. ${ }^{1-4}$ It remains one of the major causes of maternal morbidity and mortality and affects $5-8 \%$ of pregnant patients. ${ }^{5}$ The recent development in understanding the pathophysiology of preeclampsia especially the endothelial dysfunction has invoked interest in the pathological basis of its multiorgan involvement. Cardiovascular manifestations due to preeclampsia are varied which may be either secondary to hypertension, endothelial dysfunction, subclinical left ventricular dysfunction or any other unidentified pathological mechanism. ${ }^{6-11}$ In this observational study, we assessed the various cardiovascular changes in patients of preeclampsia with special reference to subclinical left ventricular dysfunction when compared with that of normal pregnancy.

\section{SUBJECTS AND METHODS}

This study was carried out in LPS Institute of Cardiology in collaboration with the Department of Obstetrics and Gynecology, GSVM, Kanpur. Women with 34 weeks gestational age having singleton pregnancy, not meeting the exclusion criteria, were enrolled in the study.

The exclusion criteria were:

- Gestational age less than 34 weeks or not sure of dates

- Known cardiac disease (e.g., structural heart disease coronary heart disease, cardiomyopathies, etc.)

- Chronic or gestational hypertension

- Renal impairment,

- Twin pregnancy and

- Diabetes mellitus 
- Obesity

- Moderate to severe anemia.

Preeclampsia diagnosis was on the basis on the National High Blood Pressure Education Program Working Group definition, also endorsed by the American Congress of Obstetricians and Gynecologists (ACOG). Preeclampsia was defined as $\geq 140 \mathrm{~mm} \mathrm{Hg}$ systolic or $\geq 90$ $\mathrm{mm} \mathrm{Hg}$ diastolic with proteinuria (>300 mg/24 hours) in a previously normotensive woman after 20 weeks of gestation. $^{2}$ Total of 30 preeclamptic patients was taken as cases which were echocardiographically assessed for various systolic and diastolic parameters and compared with that of the same number of females with normal pregnancy which served as control. Blood pressure was measured using a standard auscultatory method with the help of mercury sphygmomanometer. Blood pressure was measured in the sitting position in the right arm at the level of the heart.

Transthoracic echocardiogram was performed by single echocardiographer using a Philips IE33 system (Philips Medical Systems, Andover, MA, USA) and an S5-1 1.5/3.6 MHz transducer who was blinded to the patient's diagnosis.

Current guidelines of the American Society of Echocardiography were used to obtain Left ventricular (LV) measurements. Modified biplane Simpson's method was used to calculate LV volumes and LVEF.

LV stroke volume was calculated as the product of left ventricular (LV) outflow area and LV outflow tract VTI (velocity time integral) which was assessed by means of pulsed-wave Doppler positioned at the LV outflow tract. To assess diastolic parameters apical four chambers were used along with tissue Doppler imaging.

To obtain global longitudinal strain (GLS) three apical views were acquired at a frame rate of $40-80 \mathrm{MHz}$ for three consecutive cardiac cycles and was stored digi-

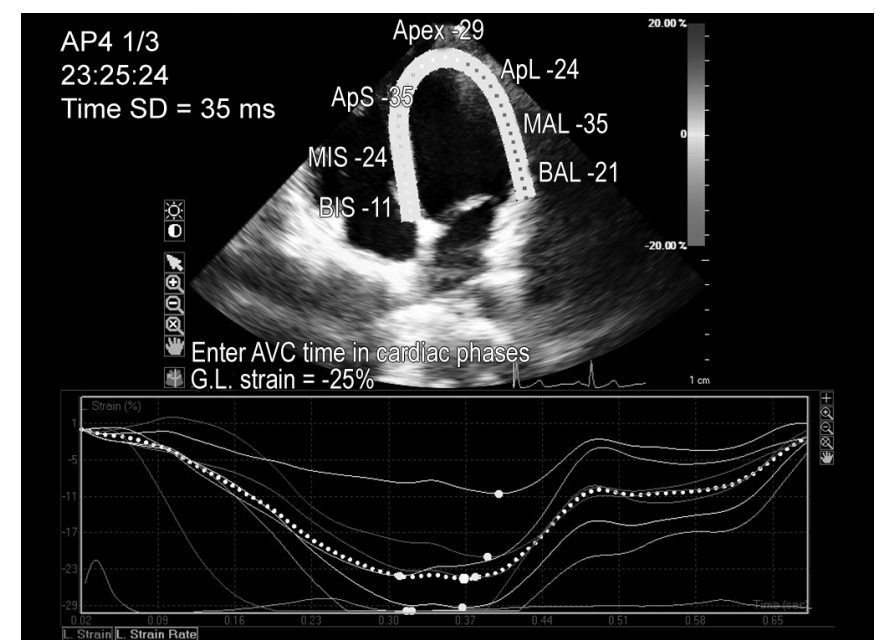

Fig. 1: 2D speckle tracking image showing longitudnal strain in normal pregnancy tally as raw data which then underwent post-processing analysis. QLAB 9 cardiac motion quantification (CMQ); Philips Medical Systems software was used for postprocessing analysis. Three sampling points were placed manually at the septal, lateral mitral annulus and the apical endocardium for each of the apical views (twochamber $(2 \mathrm{CH}), 3 \mathrm{CH}$, and $4 \mathrm{CH})$. A region of interest was then generated by the software to cover the entire thickness along the LV myocardium which was then adjusted manually to provide optimal tracking. Avoiding premature beats longitudinal 2D speckle-tracking strain values were obtained from one representative cycle. Segmental longitudinal strain values were based on the American Society of Echocardiography's 17-segment LV model. Average of regional strain (Figs 1 to 4 ) was calculated and was represented in a single bull's-eye summary. LV circumferential strain was assessed in parasternal short axis view.

SPSS software 19 statistical packages for Windows (Chicago. Inc) was used to analyze all statistical data. Continuous variables were expressed as mean \pm standard deviation (Gaussian distribution) or range, and qualitative data were expressed as a percentage. Continuous variables between the two groups were compared using the unpaired t-test.

\section{RESULTS}

The baseline features such as the age of the patient, gestational age, parity, BMI and race were compared between cases and control and they had statistically insignificant difference (Table 1).

Differences in systolic BP, diastolic BP mean arterial pressure (MAP) and TVR were higher in preeclamptic patients and had statistically significant difference with respect to control however left ventricular end-systolic

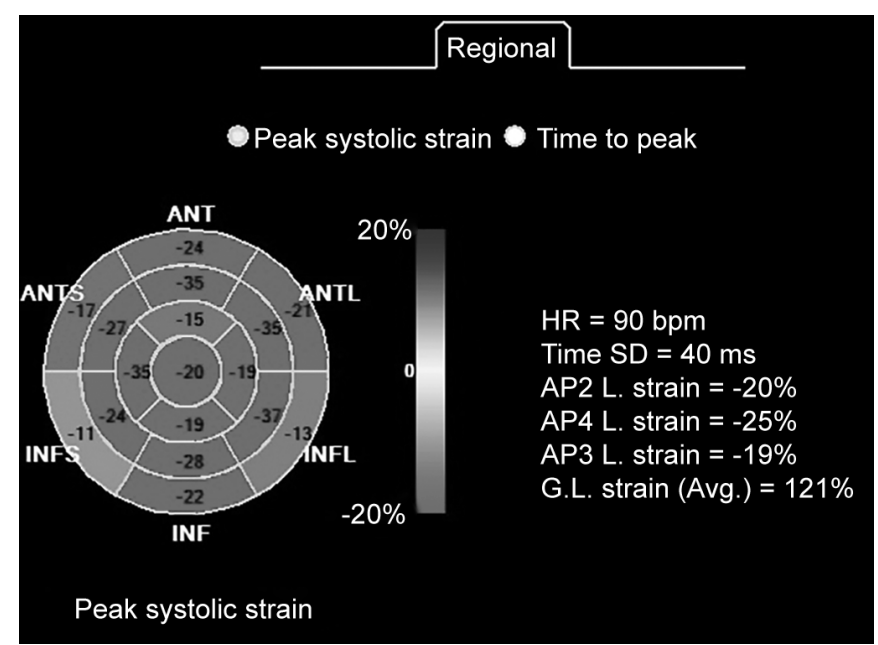

Fig. 2: Bulls eye map showing global longitudnal strain in normal pregnancy 


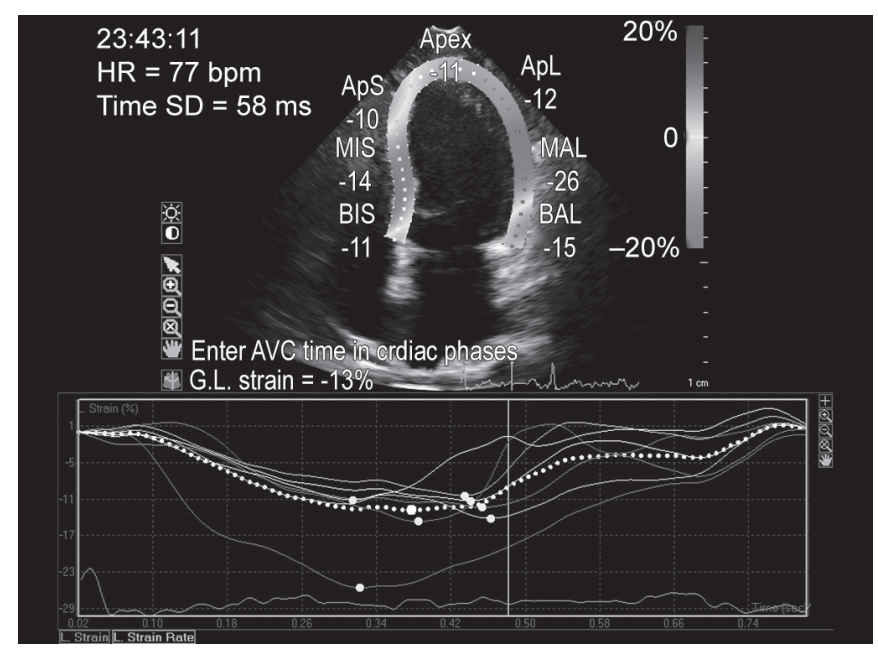

Fig. 3: 2D speckle tracking image showing longitudnal strain in preeclampsia

volume (LVESV), left ventricular end diastolic volume (LVEDV), stroke volume, cardiac output and ejection fraction showed statistically insignificant difference between two groups (Table 2).

Table 3 shows a comparison of diastolic parameters between preeclamptic subjects and control. Preeclamptic patients had more diastolic dysfunction as compared to control.

Patients with preeclampsia had more aortic, mitral and tricuspid valve regurgitation as compared with control. Subjects having global longitudinal strain less than $18 \%$ without obvious LV dysfunction on $2 \mathrm{D}$ echocardiography were said to have subclinical LV dysfunction. Subclinical left ventricular dysfunction was more in preeclamptic patients as compared to control which was assessed by LV strain imaging as a decrease in longitudinal and circumferential strain (Table 4 and Graph 1). Also, we found that systolic blood pressure had an inverse correlation with the global longitudinal strain (Graph 2).

Table 1: Baseline characteristics of cases (preeclamptic patients) and control (normal pregnancy)

\begin{tabular}{llll}
\hline $\begin{array}{l}\text { Baseline } \\
\text { characteristics }\end{array}$ & Cases & Control & $p$ value \\
\hline Age (years) & $27.4 \pm 3.8$ & $27.1 \pm 4.3$ & NS \\
Parity & $1.9 \pm 1.0$ & $1.8 \pm 1.0$ & NS \\
$\begin{array}{l}\text { Gestational } \\
\text { age (weeks) }\end{array}$ & $35 \pm 2.8$ & $35 \pm 1.1$ & NS \\
BMl (kg/m ${ }^{2}$ ) & $24.6 \pm 3.17$ & $23.4 \pm 4.14$ & NS \\
Smoking & Nil & Nil & Nil \\
$\begin{array}{l}\text { Race/ethnicity } \\
\text { Asian }\end{array}$ & 30 & & \\
White & & 30 & Nil \\
Black & & & \\
Others & & & \\
\hline
\end{tabular}

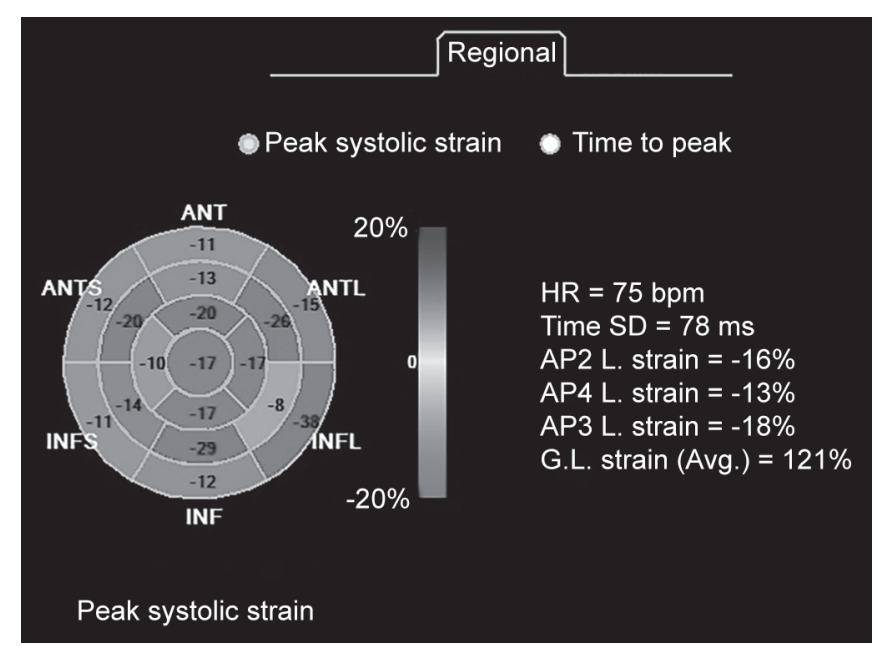

Fig. 4: Bulls eye map showing global longitudnal strain in preeclampsia

\section{DISCUSSION}

Preeclamptic patients have varied hemodynamic presentation which depends on the severity of the disease, presence of comorbidities, use of medications, gestational age and left ventricular dysfunction. ${ }^{12}$ Pathogenesis of preeclampsia is divided into two stages. The first stage is characterized by decrease placental perfusion due to inadequate development of maternal spiral arteries. This results in the release of vascular toxins and other antiangiogenic factors which causes generalized endothelial dysfunction. ${ }^{13}$ This widespread endothelial dysfunction results in hypertension, proteinuria, and edema. In our study, we found high total vascular resistance as compared to control which was similar to other studies by Valensise et al. and Poppas et al. ${ }^{14,15}$ High TVR causes an increase in afterload which causes LV hypertrophy

Table 2: Clinical and echocardiographic parameters of cases and control

\begin{tabular}{|c|c|c|c|}
\hline & Cases & Control & $p$ value \\
\hline $\begin{array}{l}\text { Heart rate } \\
\text { (beats/min) }\end{array}$ & $89 \pm 4$ & $90 \pm 4$ & 0.34 \\
\hline $\begin{array}{l}\text { Systolic BP } \\
(\mathrm{mm} \text { of } \mathrm{Hg})\end{array}$ & $158.53 \pm 10.89$ & $118.33 \pm 7.06$ & $<0.001$ \\
\hline $\begin{array}{l}\text { Diastolic BP } \\
\text { (mm of } \mathrm{Hg})\end{array}$ & $100.93 \pm 6.59$ & $71.33 \pm 7.09$ & $<0.001$ \\
\hline $\begin{array}{l}\text { Mean arterial } \\
\text { pressure } \\
(\mathrm{mm} \text { of } \mathrm{Hg})\end{array}$ & $120.14 \pm 6.23$ & $98.26 \pm 5.34$ & $<0.001$ \\
\hline LVESV (mL) & $34.67 \pm 10.12$ & $29.27 \pm 7.25$ & 0.17 \\
\hline LVEDV (mL) & $105.23 \pm 19.74$ & $103.64 \pm 11.46$ & 0.62 \\
\hline $\begin{array}{l}\text { Stroke volume } \\
(\mathrm{mL})\end{array}$ & $71.3 \pm 6.19$ & $74.2 \pm 4.22$ & 0.34 \\
\hline $\begin{array}{l}\text { Cardiac output } \\
\text { (mL/min) }\end{array}$ & $6319 \pm 1110$ & $6660 \pm 1213$ & 0.10 \\
\hline TVR (dynes/cm5) & $1568.74 \pm 156.2$ & $1123.67 \pm 86.38$ & 0.02 \\
\hline $\mathrm{EF}(\%)$ & $55.83 \pm 2.74$ & $57.38 \pm 2.33$ & 0.45 \\
\hline
\end{tabular}


Maternal Cardiovascular Hemodynamics in Preeclampsia

Table 3: Diastolic parameters between cases and control

\begin{tabular}{llll}
\hline $\begin{array}{l}\text { Doppler } \\
\text { parameters }\end{array}$ & Cases & Control & p value \\
\hline E wave & $1.03 \pm 0.17$ & $0.66 \pm 0.13$ & 0.0001 \\
A wave & $0.77 \pm 0.29$ & $0.51 \pm 0.17$ & 0.0001 \\
E/A Ratio & $1.497 \pm 0.492$ & $1.35 \pm 0.224$ & 0.3 \\
$\begin{array}{l}\text { Septal e } \\
\text { (cm/seconds) }\end{array}$ & $9.97 \pm 1.75$ & $11.29 \pm 1.43$ & 0.01 \\
$\begin{array}{l}\text { Lateral e' } \\
\text { (cm/seconds) }\end{array}$ & $11.93 \pm 2.41$ & $13.75 \pm 2.09$ & 0.01 \\
IVRT (milliseconds) & $95.91 \pm 8.73$ & $82.47 \pm 6.7$ & 0.03 \\
DT (milliseconds) & $190.27 \pm 36.73$ & $124 \pm 17.67$ & 0.02 \\
\hline
\end{tabular}

as well as an increase in filling pressure leading to diastolic dysfunction. Our study was consistent with various other studies of preeclamptic patients in which diastolic dysfunction has been reported in $30-50 \%$ of patients. ${ }^{16}$ In our study we found preeclamptic patients having lower cardiac output as compared to control. LV dysfunction either overt or subclinical is seen as associated with preeclampsia. ${ }^{17-21}$ Severe LV dysfunction in the form of peripartum cardiomyopathy is more common in preeclamptics. ${ }^{22}$ The pathophysiological basis of $\mathrm{LV}$ dysfunction in PPCM has been related to various antiangiogenic factors. A soluble version of the vascular endothelial growth factor receptor 1 (sVEGFR1), the most important of such factors are elevated in preeclampsia. ${ }^{22,23}$ Though in our study we did not find any preeclamptic patient with overt LV dysfunction, the subclinical LV dysfunction might be responsible for low cardiac output.

Advances in the field of strain imaging by echocardiography as also helped to evaluate subclinical left ventricular systolic and diastolic functions. In diastolic dysfunction attenuation of early longitudinal muscle relaxation can be observed a decrease in longitudinal strain while in the setting of a normal ejection fraction

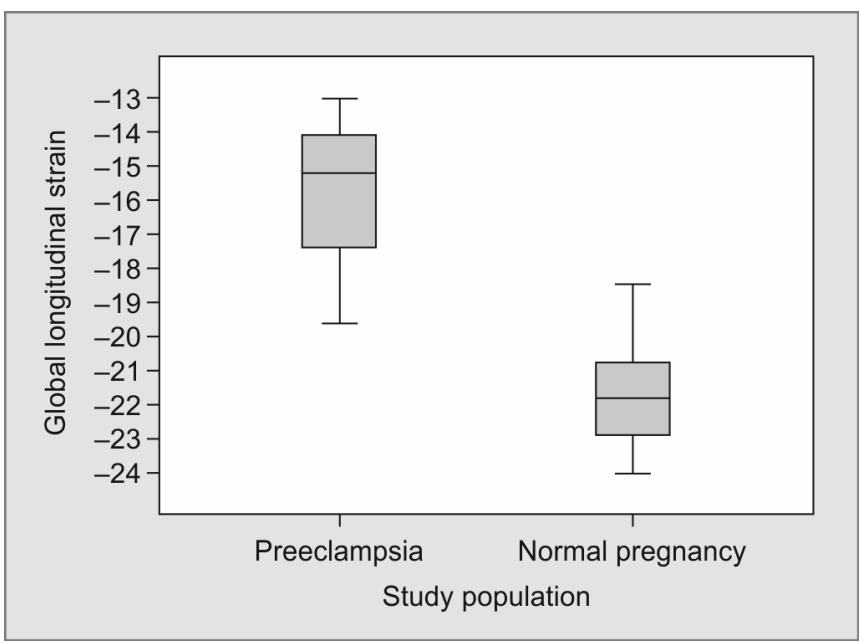

Graph 1: Box plot showing global longitudinal strain in normal pregnancy and preeclampsia
Table 4: Global longitudinal and circumferential strain along with valvular regurgitation in cases and control

\begin{tabular}{llll}
\hline & Cases & Control & $p$ value \\
\hline $\begin{array}{l}\text { Global } \\
\text { longitudinal } \\
\text { strain (\%) }\end{array}$ & $-15.63 \pm$ & $-20.86 \pm 1.52$ & $<0.001$ \\
\hline $\begin{array}{l}\text { Circumferential } \\
\text { strain (\%) }\end{array}$ & $-16.93 \pm 1.11$ & $-21.76 \pm 1.25$ & $<0.001$ \\
\hline Mitral & & & $<0.01$ \\
regurgitation & & & \\
$\quad$ Mild & 9 & 2 & \\
$\quad$ Moderate & 2 & 0 & \\
$\quad$ Severe & 0 & 0 & \\
\hline Tricuspid & & & \\
regurgitation & & 2 & \\
$\quad$ Mild & 7 & 0 & \\
$\quad$ Moderate & 1 & 0 & \\
$\quad$ Severe & 0 & & \\
\hline
\end{tabular}

\section{Aortic}

regurgitation

$\begin{array}{lll}\text { Mild } & 7 & 0 \\ \text { Moderate } & 0 & 0 \\ \text { Severe } & 0 & 0\end{array}$

changes observed in radial and circumferential strain likely represent subclinical dysfunction. The subclinical LV dysfunction may also develop due to subendocardial microvascular ischemia and fibrosis due to increased end-systolic wall stress from an increased afterload. ${ }^{17}$ In our study, we found a decrease in global longitudinal strain in preeclamptics as compared to control. The normal value of global longitudinal strain as assessed by echocardiographic techniques is usually greater than $18 \% .{ }^{21}$ Persons having global longitudinal strain less than $18 \%$ without obvious LV dysfunction on 2D echocardiography were said to have subclinical LV dysfunction. Our result was similar to the study done by Sahul et al. in which the values for longitudinal and

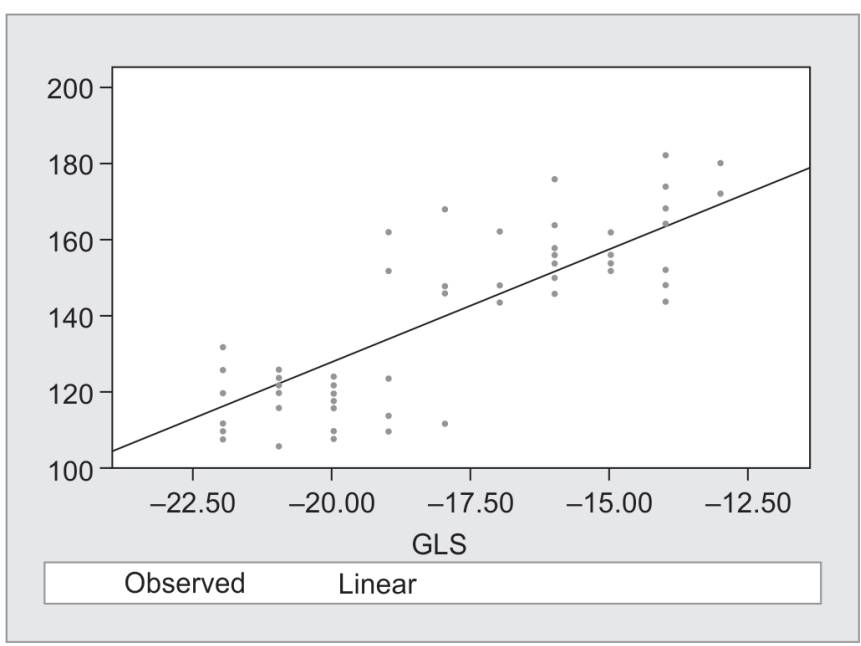

Graph 2: Dot plot showing inverse relation of blood pressure to global longitudinal strain 
circumferential strain were lower in the preeclamptic group as compared to control. ${ }^{24}$ Valvular regurgitations were more common in preeclampsia than a normal pregnancy. This may be due to subclinical LV dysfunction, altered hemodynamics or in a few cases due to change in ventricular geometry.

\section{CONCLUSION}

With this study, we can infer that pregnancies complicated with preeclampsia have various structural, hemodynamic and functional changes in the cardiovascular system which we can very easily detect by echocardiography. Knowledge of these changes may help us to understand better the pathophysiological basis of disease which may further help in managing these patients.

\section{REFERENCES}

1. Report of the National High Blood Pressure Education Program Working Group on High Blood Pressure in Pregnancy National High Blood Pressure Education Program Working Group on High Blood Pressure in Pregnancy. Am J Obstet Gynecol. 2000;183:S1-S22.

2. American College of Obstetricians and Gynecologists; Task Force on Hypertension in Pregnancy. Hypertension in pregnancy. Report of the American College of Obstetricians and Gynecologists' Task Force on Hypertension in Pregnancy. Obstet Gynecol. 2013;122:1122-1131.

3. Lowe SA, Brown MA, Dekker GA, Gatt S, McLintock CK, McMahon LP, Mangos G, et al. Guidelines for the management of hypertensive disorders of pregnancy 2008. Aust NZ J Obstet Gynaecol 2009;49:242-246.

4. Magee LA, Helewa M, et al. Diagnosis, evaluation, and management of the hypertensive disorders of pregnancy. J Obstet Gynaecol Can. 2008;30(Suppl 3):S1-S48.

5. Duley L. The global impact of pre-eclampsia and eclampsia. Semin Perinatol 2009;33:130-137.

6. Melchiorre K. Maternal cardiac chamber geometry/function and myocardial performance in pre-eclampsia: a longitudinal study from acute disease in pregnancy to two years postpartum. PhD Thesis, University of "G.d'Annunzio," Chieti, Italy. Accessed June 17, 2011.

7. Melchiorre K, Sutherland GR, et al. Maternal cardiac dysfunction and remodeling in women with preeclampsia at term. Hypertension 2011;57:85-93.

8. Melchiorre K, Sutherland GR, et al. Severe myocardial impairment and chamber dysfunction in preterm preeclampsia. Hypertens Pregnancy. 2012;31:454-471.

9. Melchiorre K, Sutherland GR, et al. Preeclampsia is associ- ated with persistent postpartum cardiovascular impairment. Hypertension 2011;58:709-715.

10. Shahul S, Rhee J, et al. Subclinical left ventricular dysfunction in preeclamptic women with preserved left ventricular ejection fraction: a 2D speckle-tracking imaging study. Circ Cardiovasc Imaging 2012;5:734-739.

11. Rafik Hamad R, Larsson A, et al. Assessment of left ventricular structure and function in preeclampsia by echocardiography and cardiovascular biomarkers. J Hypetens 2009;27:2257-2264.

12. Melchiorre K, Thilaganathan B. Maternal cardiac function in preeclampsia.Curr Opin Obstet Gynecol 2011;23:440-447.

13. RedmanCW, Sargent IL. Latest advances in understanding pre-eclampsia. Science 2005;308:1592-1594.

14. Valensise H, Novelli GP, et al. Maternal diastolic dysfunction and left ventricular geometry in gestational hypertension. Hypertension 2001;37:1209-1215.

15. Poppas A, Shroff SG, et al. Serial assessment of the cardiovascular system in normal pregnancy. Circulation 1997;95:24072415.

16. Borghi C, Esposti DD, et al. Relationship of systemic hemodynamics, left ventricular structure and function, and plasma natriuretic peptide concentrations during pregnancy complicated by preeclampsia. Am J Obstet Gynecol 2000;183: 140-147.

17. Rafik Hamad R, Larsson A, et al.Assessment of left ventricular structure and function in preeclampsia by echocardiography and cardiovascular biomarkers. J Hypetens.2009;27: 2257-2264.

18. Borghi C, Cicero AF, et al. Hemodynamic and neurohumoral profile in patients with different types of hypertension in pregnancy. Intern Emerg Med 2011;6:227-234.

19. Verlohren S, Herraiz I, et al. The sFlt-1/PlGF ratio in different types of hypertensive pregnancy disorders and its prognostic potential in preeclamptic patients. Am J Obstet Gynecol 2012;206:58.e1-58.e8.

20. Cho KI, Kim SM, et al. Impact of gestational hypertension on left ventricular function and geometric pattern. Circ J 2011;75:11701176.

21. Maynard SE, Min JY, et al. Excess placental soluble fms-like tyrosine kinase 1 (sFlt1)may contribute to endothelial dysfunction, hypertension, and proteinuria in preeclampsia. J Clin Invest 2003;111:649-658.

22. Ahmad S, Ahmed A. Elevated placental soluble vascular endothelial growth factor receptor-1inhibits angiogenesis in preeclampsia. Circ Res 2004;95:884-891.

23. Marwick TH, Leano RL, et al. Myocardial strain measurement with 2-dimensional speckle-tracking echocardiography: definition of normal range. JACC Cardiovasc Imaging 2009;2(1):80-84. 